\title{
PÓS-VERDADE, FICÇÃO, FAKE NEWS
}

\section{POST-TRUTH, FICTION, FAKE NEWS}

Ana Paula Grillo El-Jaick Universidade Federal de Juiz de Fora, UFJF, Juiz de Fora, MG, Brasil

Resumo: Este ensaio investiga o conceito de "pós-verdade" para uma história das ideias linguísticas. Seu objetivo é traçar uma genealogia dessa ideia linguística, também desenhando o que de diferente temos na contemporaneidade em relação aos pensamentos sofístico e cético antigo de que, concluímos, carrega vestígios. Entendemos que a tecnologia da internet e o poder ainda atuante das grandes mídias e do lobby de poderosas corporaçóes são elementos distintivos de nossa dita pós-modernidade em relação ao pensamento clássico. Assim, acabamos por desvelar certo cinismo contemporâneo que banaliza a estratégia cética de suspender o juízo sobre qualquer declaração assertiva.

Palavras-chave: Pós-verdade; Ficção; Fake News; Ceticismo pirrônico; Pensamento sofístico.

Abstract:This article presents an analysis of the concept of "post-truth", our aim being to set up a genealogy of this idea, putting forward the (in-)consistencies that bind "post-truth" to old sophist and skeptical thinking. Assuming that the internet technology, the influence of social media and the power of multinational corporations are distinctive elements of the so-called postmodernity, we attempt to unveil a sort of contemporary cynicism that renders (relatively) insignificant the traditional skeptical strategy of hanging up any judgment about assertive statements.

Keywords: Post-truth; Fiction; Fake News; Pyrrhonic skepticism; Sophistical thinking.

A infelicidade neste mundo é que todo o mundo tem razóes.

(Jean Renoir)

Desde que o prestigioso Dicionário Oxford incorporou a expressão pós-verdade como a "palavra do ano" em novembro de 2016, o uso do termo vem se popularizando mais e mais em nossos dias. A princípio, sua genealogia remontaria ao artigo "Um governo de mentiras" ["A Government of Lies"], 
do dramaturgo e romancista Steve TESICH, e publicado em 13 de junho de 1992 no jornal The Nation. Neste artigo, Tesich analisava a conjuntura política norte-americana e diagnosticava que havia ali uma espécie de síndrome de escândalos estatais de seguidas mentiras dos governantes. Estes simplesmente mentiam para o povo norte-americano - sem o menor esforço para sequer disfarçar as falsidades.

$\mathrm{Na}$ análise de Tesich, a Guerra no Golfo Pérsico foi um caso paradigmático: a desculpa para começar um conflito com o Iraque teria sido um aviso a Saddam Hussein de que náo violasse a integridade territorial do Kuwait. Também alegava-se (sem provas) que Saddam cultivava em seu território armas de destruição em massa. Contudo, "agora se vê que isso tudo foi mentira. Mas o fato de que o governo Bush se sentiu seguro para desclassificar os cabos eleitorais mostra que não estava mais com medo porque sabia que a verdade não teria muito impacto em nós" (TESICH, 1992, p. 13, tradução nossa $)^{1}$.

Tesich advertia, entáo, que tanto fazia se o governo falasse a verdade para seus cidadãos ou se mentisse descaradamente. Dessa maneira, os governantes podiam reconhecer que mentiram - e a vida simplesmente seguia, e era mesmo melhor fosse assim, sem as perturbaçóes de algum radical que, por ventura, se atrevesse a questionar os métodos (moralmente duvidosos) do governo. Daí a (cada vez mais conhecida) conclusão de Tesich: "De um modo bastante fundamental, nós, como um povo livre, livremente decidimos que queremos viver num mundo de pós-verdade" (TESICH, 1992, p. 13, tradução nossa) ${ }^{2}$.

A pós-verdade seria, pois, uma forma de deliberadamente não dar crédito à verdade dos fatos, mesmo quando estes são confirmados (posteriormente) por fontes confiáveis - pior: por pessoas implicadas diretamente na história em jogo. Para Tesich, essa postura foi uma escolha consciente do povo norte-americano, como uma espécie de pacto velado; porém, com consequências bastante palpáveis.

Vinte e seis anos depois, o termo usado por Tesich caiu nas graças da opiniáo pública e dos teóricos contemporâneos. Nessa linha, o norteamericano Lee McIntyre lança seu livro Pos-truth em 2018 - e se Tesich

\footnotetext{
${ }^{1}$ No original: "It now turns out that it was all a lie. But the fact that the Bush Administration felt safe in declassifying those cables shows it was no longer afraid of the truth because it knows that the truth will have little impact on us."

${ }^{2}$ No original: "In a very fundamental way we, as a free people, have freely decided that we want to live in some post-truth world."
} 
fazia duras críticas ao governo do presidente George W. Bush, o alvo agora é, abertamente, Donald Trump.

Pela aparente falta de profundidade na abordagem do tema, podese dizer que o livro de McIntyre deve ser entendido mais como um guia do que propriamente como um estudo acadêmico do problema. Encontro motivos para assim julgar quando vejo, por exemplo, que, no entendimento de McIntyre, o atual desafio à verdade (como ele coloca) seria um fenômeno inteiramente novo - até mesmo um fenômeno da era Trump, como se o atual presidente norte-americano tivesse deflorado nossa condição pós-moderna da pós-verdade. Um dos primeiros exemplos de que McIntyre se vale para defender tal teoria é a seguinte entrevista concedida por Newt Gingrich, respondendo pela Casa Branca, à repórter Alisyn Camerota, da CNN:

CAMEROTA: - [A incidência de] crimes violentos tem diminuído. A economia está crescendo.

GINGRICH: - Não está diminuindo nas grandes cidades.

[...]

CAMEROTA: - Mas, no país como um todo, os crimes violentos estão em declínio.

GINGRICH: - Aposto que o americano médio, esta manhã, não pensa que o crime está diminuindo, não pensa que estamos mais seguros.

CAMEROTA: - Mas está. Estamos mais seguros e está diminuindo.

GINGRICH: - Não, essa é apenas sua opinião.

CAMEROTA: - É um fato. Esses são fatos nacionais do FBI.

[...]

GINGRICH: - Não, mas o que eu disse é igualmente verdadeiro. As pessoas se sentem mais ameaçadas.

CAMEROTA: - Sentir, sim, eles sentem. Mas os fatos não correspondem a isso.

GINGRICH: - Como um político, eu fico com o que as pessoas sentem e deixo você com os teóricos. (MCINTYRE, 2018, p. 3-4, tradução nossa) ${ }^{3}$

Minha tese é a de que a recusa a dados estatísticos, mesmo de agências

\footnotetext{
${ }^{3}$ No original: "CAMEROTA: Violent crime is down. The economy is ticking up. GINGRICH: Is not down in the biggest cities. [...] CAMEROTA: But violent crime across the country is down. GINGRICH: The average American, I will bet you this morning, does not think crime is down, does not think we are safer. CAMEROTA: But it is. We are safer and it is down. GINGRICH: No, that's just your view. CAMEROTA: It's a fact. These are the national FBI facts. [...] GINGRICH: No, but what I said is equally true. People feel more threatened. CAMEROTA: Feel it, yes. They feel it, but the facts don't support it. GINGRICH: As a political candidate, I'll go with how people feel and let you go with the theoreticians."
} 
do próprio governo norte-americano - o que seria um ato, no mínimo, incongruente -, se mostra como uma antiga estratégia retórica que descarta silogismos lógicos e apela para entimemas ${ }^{4}$ mais afeitos ao público que pretende atingir. Nesse discurso "deliberativo" (ou "político"), conforme nomeava Aristóteles em sua arte Retórica ${ }^{5}$ o que a jornalista chama de "fatos" será sempre ignorado porque não é o que interessa ao entrevistado. Como um rétor que conhece bem seu ofício - ao menos ele mostra conhecer sua audiência -, o que importa a Gingrich é como seu eleitorado se sente. Estes foram os eleitores de Trump: pessoas que sentiam medo - o que, de fato, era verdade. Apesar dos dados colhidos pelo FBI, o fato é que as pessoas se sentem cada dia mais inseguras; têm cada vez mais a sensação de que a violência só se agrava. Não ingenuamente Gingrich apela para a "opinião" de sua oponente - afinal, o representante da Casa Branca também está se baseando em uma opiniáo, a opinião pública que elegeu Trump e que acredita na notícia de que a violência vem aumentando.

Para uma história do conceito linguístico pós-verdade, proponho uma genealogia mais elástica dessa ideia do que só remeter ao artigo de Tesich, de modo que proponho também um retorno ao embate entre verdade socrática e opiniáo (doxa) sofística. Devo atentar para o fato de que o pensamento sofístico a que me refiro aqui vem sendo reconstituído por entendidos cujo resultado de pesquisa vem desenhando esses pensadores não como mercenários que ensinavam retórica a cidadãos atenienses dispostos a lhes pagar, mas como filósofos cujo pensamento recusava dogmatismos metafísicos e, em vez disso, conferia à linguagem um poder (pode-se dizer, um tanto pós-moderno) de ordenar (novos, outros) mundos possíveis ${ }^{6}$.

No Brasil, Helena Martins, em seu texto "Três caminhos na

\footnotetext{
${ }^{4} \mathrm{Na}$ sua arte Retórica, Aristóteles define "entimema" como uma espécie de silogismo retórico: uma vez que um silogismo lógico é (muito geralmente) ineficaz para convencer uma multidão, o bom retórico deve se valer de entimemas que de fato persuadam sua plateia acerca do tema ali tratado. É necessário explicar que não estou considerando, de forma alguma, Aristóteles um sofista. Antes, estou aqui me valendo do texto do estagirita em que este desvela o método dos retóricos, sendo que os sofistas eram mestres dessa téchne.

${ }^{5}$ Como se sabe, na Retórica Aristóteles estabelece três gêneros de retórica: deliberativo (ou político), judicial (ou forense) e epidíctico (ou demonstrativo) (ARISTÓTELES, Retórica 1358b).

${ }^{6}$ No centro desta argumentação, certamente, está a polissêmica expressão logos. De acordo com o confiável Dicionário Liddel and Scott Greek - Emglish Lexicon, entre várias definiçóes, o termo significa "a palavra ou aquilo que expressa o pensamento e o próprio pensamento" (no original: "the word or that by which the inward thought is expressed and the inward thought itself").
} 
filosofia da linguagem", defende que o pensamento sofístico sobre a linguagem humana se revela como certa protoimagem de uma perspectiva "radicalmente pragmática da linguagem e do sentido" (MARTINS, 2011, p. 449). Concordo que a sofística coloca em questão o paradigma referencial da linguagem, pois, nesta perspectiva, o logos não diz o real. Exemplo desse pensamento vemos no fragmento B. III, de Górgias:

Assim como o visível não pode tornar-se audível, ou o contrário, assim também o ser que subsiste exteriormente a nós não poderia tornar-se nosso discurso. Não são pois os seres que nós revelamos àqueles que nos cercam; nós só lhes revelamos um discurso que é diferente das substâncias. Se é assim, o discurso não manifesta o objeto exterior; pelo contrário, é o objeto exterior que as manifesta no discurso. (Fragmento B. III)

Da mesma forma como ao dizermos algo não materializamos coisas do mundo, também as coisas do mundo não se transformam em discurso. São instâncias para sempre distintas - não podemos ver uma voz aguda ou ouvir a cor azul. Por isso é que, quando usamos a linguagem, não revelamos o real, não dizemos fatos: o discurso não é a mesma coisa que as coisas do mundo. Logo, ao contrário de afirmarmos que a linguagem diz o real, dizemos que o real se faz na linguagem.

Sem temer a anacronia, mas desejando mostrar a atualidade e vivacidade do pensamento sofístico, ratifico a hipótese de que este pensamento seja um embriâo de uma concepção de linguagem como ação ${ }^{7}$. Dessa forma, conforme já adiantei, alinho-me a essa espécie de renascimento do pensamento sofístico que vem se operando recentemente, em que, podemos dizer, os sofistas são vistos como pós-modernos avant la lettre, pois já tinham percebido o poder demiúrgico da linguagem, expressáo cunhada por Barbara Cassin ([1995] 2005), outra teórica que vem militando por uma reabilitação sofística. Cassin faz uso desse dito quando analisa a seguinte passagem do Elogio de Helena, de Górgias: "O discurso [logos] é um grande soberano que, por meio do menor e do mais inaparente dos corpos, realiza os atos mais divinos, pois ele tem o poder de dar fim ao medo, afastar a dor, produzir alegria, aumentar a piedade" (GÓRGIAS, Elogio de Helena) ${ }^{8}$. Como um deus incorpóreo, o logos tem o poder de potencializar afecçôes,

\footnotetext{
${ }^{7}$ Sobre a questão do anacronismo, recorro sempre a Francis Wolff, para quem não faz sentido se falar em anacronia quando se estuda o pensamento grego antigo - afinal de contas, em última instância, o anacronismo é, simplesmente, inevitável (WOLFF, 2008).

${ }^{8}$ Tradução para o português tirada do livro de Barbara CASSIN (2005 [1995]).
} 
fabricar paixôes, apaziguar humores. O logos tem a capacidade de organizar o mundo de outra(s) forma(s).

Assim, o discurso não nos dá acesso ao mundo em si - o que temos são discursos (que nunca dáo conta, mas que falam do/) sobre o mundo. Dessa forma, nosso conhecimento sobre o mundo é discursivo. Aí se entende a fúria platônica contra os sofistas ${ }^{9}$. No caso em investigação, a ideia gorgiana de linguagem coloca em xeque a capacidade humana de entendimento sobre o real - coloca em risco a possibilidade de haver uma verdade.

Nesse sentido, vejamos ainda outro fragmento de Górgias:

Nada há que possa ser conhecido. Se pudesse ser conhecido, não poderia ser comunicado. Se pudesse ser comunicado, não poderia ser compreendido. (Sobre o não ser ou sobre a natureza, Fragmento I)

Mais uma vez reconhecemos a retórica sofística como pertencente à tradição cética ocidental ${ }^{10}$ - ainda que os filósofos que passaram por nossa história com essa alcunha de "sofistas" mostrem diferenças substanciais em seus pensamentos, traços há que demostram um entendimento comum quanto a certa incomunicabilidade do real tal que, consequentemente, estaríamos fadados à ignorância absoluta de alguma verdade última sobre o mundo exterior.

Isso quer dizer que, como nossa linguagem faz mais do que nos representar as coisas mundanas e, ao mesmo tempo, náo nos diz o real uma vez que, conforme já vimos, nome e coisa são de naturezas distintas -, entáo, não pode haver comunicaçâo sobre (os fatos,) a realidade. A retórica gorgiana mostra que, mesmo que pudéssemos ter acesso ao conhecimento à verdade - do mundo, tal conhecimento seria indizivel.

O Fragmento I acima faz um último movimento, uma última torção: ainda que consideremos que possamos comunicar conhecimento - verdade -, tal conhecimento náo seria compreendido por outrem, posto que a

\footnotetext{
${ }^{9}$ Uma evidência textual desse embate intelectual pode ser vista no diálogo Crátilo, em que Platão coloca as seguintes palavras na boca de Sócrates: "Então vejamos agora, Hermógenes, se és também de parecer que com os seres se dá o mesmo, possuindo cada um sua existência particular, como dizia Protágoras quando afirmou que o homem é a medida de todas as coisas, e que, por isso, conforme me parecerem as coisas, tais serão elas para mim, como serão para ti, conforme te parecerem. Ou és de opiniấo que sua essência seja, de algum modo, permanente?" (PLATÃO, Crátilo 386a).

${ }^{10}$ Sobre isso, remeto o leitor ao texto de Danilo MARCONDES (1997) e previno que a questấo cética ainda voltará ao final deste artigo.
} 
linguagem não nos dá acesso à realidade última do mundo exterior, mas só nos diz opinióes instáveis, mutáveis sobre o que se nos aparece num determinado momento.

Daí Górgias relatar o logos como um grande senhor ao qual estamos como que submetidos (ou: subjugados ao seu poder demiúrgico). Novamente testemunhamos o escândalo de Platão ao vislumbrar este perigo no labiríntico pensamento gorgiano: a retórica de Górgias dissolve qualquer possibilidade de uma verdade essencial. Assim, tomar parte no discurso seria como que criar fiçôes - tentar falar sobre as coisas do mundo já seria organizar alguma narrativa ficcional. Mesmo se buscarmos dizer a verdade dos fatos, ela, simplesmente, será um discurso falso.

Os sofistas, dessa maneira, teriam mostrado que, ao se dominar a retórica, todas as teses, tudo que se quiser provar, pode ser provado em filosofia. Advogo pela reconstituição histórica de se ligar essa ideia linguística da Antiguidade clássica de um "poder demiúrgico" da linguagem como força de ordenação das coisas do mundo à dita pós-verdade contemporânea e seu subproduto, as notícias falsas [fake news] ${ }^{11}$, como "novo" reconhecimento de que o logos realiza atos os mais divinos: criam, ordenam fatos fictícios.

Então, a incensada "pós-verdade" definida pelo Dicionário Oxford como um adjetivo "que se relaciona ou denota circunstâncias nas quais fatos objetivos têm menos influência em moldar a opinião pública do que apelos à emoção e a crenças pessoais" ${ }^{12}$ parece ter, pelo menos, dois mil anos. Afinal, o prefixo "pós" de "pós-verdade", confirma McIntyre, não é temporal (como o é em "pós-guerra"), mas eclipsa aquilo que determina - ou, como bem colocou o psicanalista Christian Dunker em forma de pergunta: "O que entender por verdade quando se lhe acrescenta este prefixo que a aposenta: a pós-verdade"? (DUNKER, 2017, p. 11). Então, a historiografia dessa ideia linguística, repito, é muito anterior aos presidentes norte-americanos, posto que estratégias retóricas há séculos desafiam uma verdade para além de opinióes sobre o real. Também nesse sentido, parece interessante

\footnotetext{
${ }^{11}$ Pode-se dizer que fake news é uma notícia em que claramente há a intençấo de influenciar outros. Uma possível definiçāo encontramos em MCINTYRE (2018, p.74) ao se referir aos sites de fake news: "Os sites de notícias falsas se usam das premissas do jornalismo para espalharem o que sabem ser falso" (no original: "Fake news sites use the pretenses of journalism to spread what they know to be false").

${ }^{12}$ Essa definição de "pós-verdade" está disponível em: https://www.nexojornal.com.br/ expresso/2016/11/16/O-que-é-'pós-verdade'-a-palavra-do-ano-segundo-a-Universidade-deOxford. Acesso em: 30 jan. 2017. No original: "[...] relating to or denoting circumstances in which objective facts are less influential in shaping public opinion than appeals to emotion and personal belief."
} 
examinarmos como a crítica contemporânea aos discursos pós-verdadeiros pode se aproximar aos conselhos aristotélicos para o bom retórico. Vejamos.

Primeiramente, observemos um preocupado McIntyre que define o comportamento político atual (neste caso, o autor se referia à campanha da Grã-Bretanha para se livrar do Brexit) como "não necessariamente para dizer que os fatos não importam, mas em vez disso uma convicçáo de que os fatos podem sempre ser sombreados, selecionados, e apresentados dentro de um contexto político que favorece uma interpretação da verdade sobre outra" (MCINTYRE, 2018, p. 6, tradução nossa) ${ }^{13}$.

Agora, vejamos um didático Aristóteles defender (em outros termos e tempos, está claro) a busca por se favorecer as características que nos servem em nosso discurso, selecionando aquilo que pode vir a nosso favor e deixando à margem o que não nos beneficia. Enfim, se na base do discurso retórico estão os fatos, estes podem ser, digamos assim, moldáveis:

\begin{abstract}
No que concerne ao elogio e à censura, devemos assumir como idênticas as qualidades existentes ao que lhes estấo próximas: por exemplo, que o homem cauteloso é reservado e calculista, que o simples é honesto, e o insensível é calmo; e, em cada caso, tirar proveito destas qualidades semelhantes sempre no sentido mais favorável; por exemplo, apresentar o colérico e furioso como franco, o arrogante como magnificente e digno, e os que mostram algum tipo de excesso como se possuíssem as correspondentes virtudes; por exemplo, o temerário como corajoso e o pródigo como liberal. (ARISTÓTELES, Retórica 1367a-1367b)
\end{abstract}

No discurso, entáo, é possível fazer o parecer ser: o excesso pode ser virtude; o aparente defeito, uma bem-vinda qualidade. Isso coloca em xeque como as coisas verdadeiramente - realmente - são. Assim, cabe ao bom retórico organizar um mundo possível (um certo mundo) com seu discurso, sabendo que, para cada caso, um remédio (um pharmakós) será indicado - com certa medida. Entendo que uma ressignificação dessa técnica, dessa arte (téchne), pode ser vislumbrada quando a Conselheira da Casa Branca Kellyanne Conway defende que o governo norte-americano trabalha com "fatos alternativos" ["alternative facts"] - por isso, para a Casa Branca, o número de participantes na posse de Trump é muito maior do que as evidências mostram (cf. KURTZLEBEN, 2017; MCINTYRE, 2018, p. 6).

Devo salientar que, neste ensaio por uma genealogia de uma brevíssima

\footnotetext{
${ }^{13}$ No original: "This is not necessarily a campaign to say that facts do nor matter, but instead a conviction that facts can always be shaded, selected, and presented within political context that favors one interpretation of truth over another."
} 
história da ideia de "pós-verdade", devo considerar a hipótese de que essa espécie de surto da dita pós-verdade poderia ser uma consequência de um ideário pós-moderno (possibilidade essa também considerada pelo há citado McIntyre): concepçóes pós-modernas de que, por exemplo, não há um texto primordial teriam nos levado a conclusóes como a igualação entre tradução/ (outro) texto original, original/plágio etc. - o que, por sua vez, teria nos conduzido à aporia de que todo texto é válido, mesmo se falso. Entretanto, entendo que os Departamentos universitários de Filosofia e Literatura, ao menos no Brasil, não têm tamanha influência sobre a opinião pública. $\mathrm{O}$ poder dos acadêmicos das Humanidades não chega a ter tal penetração política, logo, não muda o pensamento de uma era a ponto de, por causa desses professores, vivermos em uma era da (famigerada) pós-verdade.

Então, uma pergunta que se pode formular a esta altura é: se a pós-verdade parece remeter à nossa tradição ocidental grega, de Sócrates, Platáo e Aristóteles $^{14}$ contra os sofistas, no que ela se diferiria, na contemporaneidade, daquele embate? Uma hipótese é a de que a internet seja o grande diferenciador de nosso tempo: jamais tivemos tamanha facilidade para produzir e difundir notícias (também falsas) como temos devido à rede mundial de computadores. Assim, se na Grécia antiga os debates se restringiam aos cidadãos atenienses presentes na ágora em um determinado momento, agora uma discussão acontece em rede mundial, no Facebook, no Twitter, etc. - e o bater de asas de uma borboleta em Minas Gerais pode, sim, criar um furacão em Paris.

Antes e além disso, ainda há o poder midiático - ausente na antiguidade da forma como conhecemos hoje, supostamente superado pelas redes sociais da internet, mas que ainda demostra força política. No Brasil, as pesquisas de audiência confirmam o que uma primeira impressão já faz suspeitar: a agência de notícias de maior alcance entre os brasileiros é a Rede Globo de jornalismo. Com relação às fake news, é interessante notar que a Globo News, canal pago de jornalismo da Globo, e o site G1, local da internet dessa mesma agência de notícias, recentemente abrigam o espaço "Fato ou fake - serviço de checagem de conteúdos suspeitos". Ao se abrir o link da G1, vemos no lado esquerdo da tela os políticos brasileiros candidatos à presidência da República neste ano de 2018 e, ao lado da foto de cada um, a chamada "Veja o que é \#FATO ou \#FAKE na entrevista de ao/à

${ }^{14}$ Lembremos a notória definiçấo de verdade aristotélica: "Dizer do que é que não é, ou do que nẫo é que é, é falso, enquanto dizer do que é que é, e do que não é que não é, é verdade" (ARISTÓTELES, Metafísica 1011b25). 
Neste caso, poderíamos lembrar outra escola helenística da antiguidade clássica - todavia, defendo que apenas seu nome, mesmo assim ressignificado no seu uso atual, faz sentido aqui, e não o método filosófico tal como era pregado: os cínicos. Tal menção, reconheço, não é algo original: o próprio DUNKER (2017, p. 17), já referido anteriormente, lembra "o cinismo como discurso básico do espaço público e da vida laboral”.

Entendo que, quando uma grande agência de notícias finca um espaço que diz averiguar o que é falso no discurso político, isso pode ser tido como um exemplo de cinismo contemporâneo no sentido de numa espécie de banalização do engodo ${ }^{15}$. Quando líderes de governo - e pretensos líderes de governo - tomam a palavra de modo comprovadamente falso e a única consequência é que um "termômetro da verdade" de uma grande mídia tende para o fake em vez de para o verdadeiro, então parece que todos eles, juntos, estão, inescrupulosamente, desprezando nossa confiança, nossa razão. O cinismo está em que jornalistas e políticos (nos casos aqui analisados) parecem se aproveitar da falta de univocidade de resposta para questóes milenares do tipo "o que é a verdade?", e acabam se autoeximindo de responderem por qualquer compromisso profissional com alguma mínima tentativa de objetividade. Em outras palavras: uma vez comprovado que uma objetividade absoluta é uma ambição positivista sempre frustrada, então, dissimuladamente, inventam-se notícias e/ou consideram-nas dignas de atençáo tanto quanto notícias que relatam acontecimentos. $\mathrm{O}$ cinismo também se mostra quando sequer há a preocupação de se disfarçar as estratégias, os furos, as máscaras dos falsários.

Náo estou aqui afirmando que estes retóricos pós-modernos do jornalismo e da política tenham lido Platão, Górgias, Aristóteles. Esse é um dos movimentos que McIntyre faz em seu livro: postular a ideia de que talvez seja culpa de pensadores "pós-modernos" a onda de notícias falsas que tem se formado nas redes sociais. Vejo aí uma irrealidade de se figurar filósofos como Derrida ou Deleuze como formadores de opinião do eleitorado médio de qualquer nação contemporânea. Para MCINTYRE (2018, p. 17ss), na medida em que debates acadêmicos - como os inflamados por esses pensadores - garantem a impossibilidade de uma verdade objetiva e que esse descrédito tem sido usado para se atacar o discurso científico, entáo a filosofia teria como que incentivado essa era da pós-verdade.

Em vez disso, postulo por outro elemento em nossa historiografia

\footnotetext{
${ }^{15}$ É preciso deixar claro que a G1 não é a única agência de notícias no mundo que está promovendo esse tipo de jogo; se me detenho a esse exemplo é porque, como já disse anteriormente, esta é a rede jornalística de maior audiência no Brasil.
} 
da ideia linguística de pós-verdade: a tradição cética. Para desenvolver este (ainda que breve, dada a natureza deste texto) exame, investigarei aquele que é uma de nossas maiores fontes do ceticismo ocidental, Sexto Empírico (séc. II-III d.C.). Apesar de este filósofo e médico grego não gozar de muito prestígio em nossa história filosófica, seus escritos são de grande valia, pois, por eles, conhecemos o modo de vida daquele que é tido como um dos primeiros céticos de nossa tradição ocidental, Pirro de Élis.

$\mathrm{O}$ ceticismo pirrônico, ao contrário do que pode parecer à primeira vista, não prega a inapreensibilidade da verdade. $\mathrm{O}$ cético pirrônico, ao empreender uma investigação filosófica, encontra respostas contrárias em relação ao seu objeto de pesquisa. Tais respostas (no mínimo duas), para ele, têm a mesma força de argumentação, apesar de serem opostas - isso impede que se possa escolher as duas ao mesmo tempo, uma vez que seria como afirmar simultaneamente $a$ e não $a$. Dada a equipolência de argumentos contrários, o cético pirrônico se vê impossibilitado de decidir qual asserção é a verdadeira. Por isso é que só lhe resta suspender o juízo (epoché) sobre o assunto em questão. Ao suspender o juízo, qual uma sombra segue um corpo, o cético pirrônico encontra aquilo que, desde o início, buscava: a tranquilidade, a quietude, a imperturbabilidade da alma (a ataraxia) - visto que o pirronismo, como filosofia helenística, tem como fim a felicidade. Nas Hipotiposes pirrônicas $^{16}$, obra de Sexto Empírico em que este esboça o modo de vida cético, o autor compila cinco tropos de Agripa $^{17}$ (além de dez de Enesidemo) que levariam à suspensão do juízo. Esses tropos são: (i) conflito, (ii) regresso ao infinito, (iii) relatividade, (iv) hipótese, e (v) ć́rculo vicioso.

Se trago os tropos de Agripa para este ensaio é porque acredito que o descrédito contemporâneo de que sofre o discurso científico me parece ser uma conjunção desses modos, principalmente de dois deles: o do regresso ao infinito e o da hipótese. De acordo com o tropo do regresso ao infinito, o

\footnotetext{
${ }^{16}$ As Hipotiposes pirrônicas correspondem à principal fonte informativa sobre o ceticismo pirrônico. Elas formam uma introduçấo ao pirronismo, subdividida em três livros. O Livro I é uma explicação geral do que é o ceticismo pirrônico. Nele, Sexto Empírico diferencia o pirronismo das filosofias dogmáticas e apresenta o arsenal cético. Os dez tropos de Enesidemo consomem a maior parte desse Livro. Os Livros II e III são argumentaçôes específicas - Sexto Empírico empunha as armas céticas antes apresentadas para atacar posiçóes dogmáticas. Como os dogmáticos dividiram a filosofia em três partes, é nelas que ele vai se deter de maneira específica. O Livro II agrupa argumentos contra a lógica (abarcando náo só o que hoje chamamos de lógica, mas também a epistemologia); e o Livro III é dedicado à física (abrangendo o que tendemos agora a chamar metafísica e filosofia da ciência) e à ética.

${ }^{17}$ Filósofo cético do qual nada se sabe, a nấo ser que floresceu depois de Enesidemo (ANNAS; BARNES, 2000, p. xviii).
} 
pirrônico sempre pede mais provas, garantias àquele que afirma uma verdade (a quem o pirrônico chama de "dogmático"). Contudo, ao oferecer uma nova prova, o pirrônico ainda pedirá a prova da prova - e assim sucessivamente, ad infinitum. Constata-se que essa atitude cética leva à suspensão do juízo, já que não há, em última instância, uma prova absoluta ${ }^{18}$.

Esse tropo, entendo, conjuga-se ao da hipótese. Vejamos este último:

Tem-se o modo baseado na hipótese quando os dogmáticos, sendo forçados a recuar ao infinito, tomam como ponto de partida algo que não estabelecem através da argumentação, e que julgam por bem tomar simplesmente, sem demonstração. (PH I 168) ${ }^{19}$

Verifica-se que o cético considera "sem demonstração" aquilo que não tem uma prova absoluta, um fundamento essencial, último - eterno, imutável. Ou seja: ao não encontrar um fundamento absoluto como prova de frases declarativas, o cético descarta qualquer tipo de asseveração ${ }^{20}$.

Foi dito logo acima haver uma conjunção entre os tropos do regresso ao infinito e o da hipótese, mas os outros também podem ser reconhecidos no cenário atual da dita pós-verdade, como o do conflito (diaphonia). Segundo J. Barnes, o desacordo era um fato filosófico: "Havia - o que não é de surpreender - desacordo sobre a própria atitude quanto ao desacordo" (BARNES, 1999, p. 5). No entanto, pensadores como Galeano e Aristóteles não discordavam pelo mero prazer de discordar. Era como mola propulsora à pesquisa rumo ao conhecimento verdadeiro que a diaphonia era praticada por eles. Para Sexto Empírico, é obscuro tudo sobre o que há desacordo (SEXTO EMPÍRICO, Contr. Ret. 108). Mas não se trata apenas de sustentar diferentes pontos de vista. É preciso que haja conflito entre, no mínimo, duas partes (sejam elas filósofos, leigos, ou que o conflito se faça entre no

${ }^{18}$ Em Contra os lógicos (M VIII 314), Sexto Empírico reproduz a definiçấo estoica de prova: "Uma prova é um argumento (logos) que, através de premissas concordes, revela por dedução uma conclusão não evidente".

${ }^{19} \mathrm{PH}$ é abreviação de Hipotiposes pirrônicas. Essa tradução é de P. R. de Oliveira.

${ }^{20}$ Sobre isso é necessário prevenir o leitor de que há já um grande debate entre os especialistas do ceticismo pirrônico em relaçáo a qual seria o alcance da époche pirrônica. Dois tipos de ceticismo nos aparecem, dependendo das respostas: (i) o pirronismo rústico, que rejeita qualquer crença e, no que tange à linguagem, náo dá qualquer assentimento a qualquer questão, seja ela filosófica ou não; e (ii) o pirronismo urbano, que dirige sua descrença aos assuntos dos sábios, filósofos e cientistas, por assim dizer, mas que acredita no senso comum - o que, transferindo para o campo linguístico, equivaleria a restringir o não assentimento às frases declarativas (BARNES, 1997, p. 61-62; cf. PH I 13) 
mínimo dois órgãos sensitivos etc.), e que este desacordo seja indecisivo. Uma vez satisfeitas essas condições, o fato mesmo de haver um conflito insolúvel entre opinióes dissonantes leva à suspensão do juízo.

Novamente me utilizarei do livro de McIntyre, por entender que o exame que este opera sobre a indústria tabagista é um bom exemplo do uso da habilidade cética do conflito. Porém, talvez seja oportuno fazer aqui um adendo: se me vali demasiadamente deste livro, isso se deveu mais à escassez de material específico sobre "pós-verdade" do que propriamente por concordar com McIntyre. Sua obra mostra fraqueza quando, a todo momento, o autor aposta que a solução para a pós-verdade e as fake news está em se atentar aos fatos - quando bem se sabe que esse é justamente o problema. McIntyre recrimina a ameaça à realidade, quando a questão (sempre) posta, conforme defendo neste texto, é o ceticismo em relação ao mundo exterior como ele realmente é para além das aparências fenomênicas (phainomena). Enfim, feito esse adendo, remeto o leitor novamente a McIntyre quando este cita Rabin-Havt, autor de Lies, Incorporated:

O Comitê de Pesquisa da Indústria do Tabaco foi criado para lançar dúvidas sobre o consenso científico de que fumar cigarros causa câncer ${ }^{21}$, convencer a mídia de que havia dois lados na história em relação aos riscos do tabaco e que cada lado deveria ser considerado com igual peso. Finalmente, procurou evitar que os políticos prejudicassem os interesses econômicos das companhias de tabaco. (RABIN-HAVT apud MCINTYRE, 2018, p. 23) ${ }^{22}$

A artilharia cética está a postos: como não há consenso absoluto sobre determinado assunto (no caso, os males causados pelo cigarro), e como as diferentes proposiçôes sobre um tema devem ser consideradas como igualmente fortes, estamos para sempre presos à armadilha da aporia cética.

Dito isso, uma possível crítica ao pensamento cético é que, no fim das contas, ele se desvela como a outra face da mesma moeda do essencialismo - ambos só se contentam com uma verdade absoluta, uma certeza para além de contingências. Porém, a filosofia da ciência e também os cientistas das ciências ditas hard admitem que tal certeza é inalcançável - o discurso

${ }^{21}$ Em Lies, Incorporated, Rabin-Havt mostra que esse comitê foi criado para criar pesquisas falsas (RABIN-HAVT apud MCINTYRE, 2018, p. 25).

${ }^{22}$ No original: "The Tobacco Industry Research Committee was created to cast doubt on scientific consensus that smoking cigarettes causes cancer, to convince the media that there were two sides to the story about the risks of tobacco and that each side should be considered with equal weight. Finally it sought to steer politicians away from damaging the economic interests of the tobacco companies." 
científico tem de ser falseável à pena de se tornar, ele próprio, um dogma, questâo fé. Em tempos de pós-verdade, esse infinito colocar-se em questão que é a própria razão de ser da ciência torna-se evidência de que todo discurso científico não passa de mera hipótese - e isso quer dizer que não se deve confiar nenhum crédito à ciência; que ao discurso dos astrônomos deve ser dado o mesmo valor que ao discurso dos astrólogos, por exemplo.

Defendo, entáo, que a dúvida em torno da prova sobre o discurso científico mostra-se como uma atitude cética pirrônica - contemporânea. Além disso, novamente o cinismo se revela: como comprovou Rabin-Havt, se já não há alguma pesquisa que mostre desacordo com uma teoria "pouco lucrativa”, então cabe à grande corporação manufaturar esse conflito teórico, como fez o comitê financiado pela indústria tabagista, criado para criar pesquisas falsas (RABIN-HAVT apud MCINTYRE, 2018, p.25).

Além disso, concordo também que esse cinismo aparece conjugado a uma espécie de ceticismo linguístico contemporâneo, não apenas flagrado por mim. Lembro-me aqui pelo menos de Talbot TAYLOR (1992), que fala em um ceticismo comunicacional, Martha NUSSBAUM (1985), que pensa em uma sofistica contemporânea, Martin STONE (2000), que se refere a uma sempre iminente ameaça cética, e do crítico literário Michael FISCHER (1989), que reconhece a presença de um ceticismo literário atual. Com relação ao nosso caso em análise, quando se reconhece a impossibilidade de um discurso epistemológico definitivo, ceticamente suspende-se o juízo sobre a admissibilidade de qualquer asseveração.

Dessa maneira e novamente, o ponto a desvendar seria o que essa dita era da "pós-verdade" teria para ser considerada diferente do debate retórico/ cético antigo. Uma primeira conclusão que se apontou foi a tecnologia atual, que nos abriu o mundo da internet - o que nos proporcionou a troca de informaçôes em nível mundial em uma velocidade nunca antes possível. Uma segunda conclusão a que se chegou foi o poder (ainda) expressivo da mídia contemporânea, que, com sua capacidade de espetacularização, acabou por banalizar o engodo, já que normaliza as manobras políticas que intentam nos ludibriar. Por fim, defendo uma terceira hipótese: a de que, agora, diferentemente da antiguidade clássica, essa disputa retórica mobiliza cifras astronômicas. Se Sócrates se preocupava com o soldo dos sofistas, hoje em dia o lobby das grandes corporaçôes decide o destino de milhares de dólares em investimentos - e lucros. Por isso, vale a pena produzir dúvidas na população - o ceticismo, agora, é bastante lucrativo. Igualmente, o cinismo de que tudo o que temos é mera opinião não é nada 
ingênuo, tampouco fruto de alguma teoria epistemológica que reconhece a falibilidade das verdades científicas: a dúvida não é promovida como uma estratégica argumentativa para se chegar a um conhecimento posterior ${ }^{23}$, mas é criada por interesses financeiros.

Por fim, espero ter traçado, ainda que breve, mas firme caminho histórico do conceito de "pós-verdade" para uma história das ideias linguísticas, reconhecendo sua linhagem grega. Conforme já disse, longe estou de defender aqui que os atuais criadores de fake news sejam leitores vorazes, por exemplo, de Sexto Empírico - pelo contrário, creio mesmo que nunca ouviram falar nesse filósofo e médico grego. Minha investigação objetivou traçar um percurso histórico e examinar o que nos diferencia de nossa tradição clássica. De resto, esta dita era da "pós-verdade", fabricante de fake news, com aparato tecnológico mais arrojado, segue a premissa de assegurar dominação econômica, política, intelectual de uns por outros.

\section{Referências}

ANNAS, J.; BARNES, J. Introduction. In: SEXTUS EMPIRICUS. Outlines of Scepticism. Cambridge: Cambridge University Press, 2000. p. xi-xxxi.

ARISTÓTELES. Retórica. Prefácio e introdução: Manuel Alexandre Júnior. Tradução e notas: Manuel Alexandre Júnior; Paulo Farmhouse Alberto; Abel do Nascimento Pena. São Paulo: Editora WMF Martins Fontes, 2012 (Coleção Obras Completas de Aristóteles).

BARNES, J. The toils of scepticism. Cambridge: Cambridge University Press, 1999.

. The Belifs of a Pyrrhonist. In: BURNYEAT, M.; FREDE, M. (Ed.). The Original Sceptics: a controversy. Indianapolis/Cambridge: Hackett Publishing Company, Inc., 1997. p. 1-29.

CASSIN, B. Como a política é uma questão de logos. In: . O efeito sofístico: sofística, filosofia, retórica, literatura. Tradução de Ana Lúcia de Oliveira, Maria Cristina Franco Ferraz e Paulo Pinheiro. São Paulo: Ed. 34,

\footnotetext{
${ }^{23}$ Faço aqui referência ao texto "A tradição cética", em que Danilo Marcondes considera quatro concepçōes de ceticismo na história ocidental: (i) o ceticismo como estratégia argumentativa; (ii) o ceticismo como discussão da problemática epistemológica; (iii) o ceticismo como modo de vida; e (iv) o ceticismo como argumento para mostrar a falsidade do conhecimento racional, de acordo com o qual só resta o caminho da fé (o chamado ceticismo fideísta).
} 
[1995] 2005.

DUNKER, C. Subjetividade em tempos de pós-verdade. In: ; et. all. Ética e pós-verdade. Porto Alegre: Dublinense, 2017.

FISHER, M. Stanley Cavell and literary skepticism. Chicago \& London: The University of Chicago Press, 1989.

GÓRGIAS. E. H. In: CASSIN, B. O efeito sofístico: sofística, filosofia, retórica, literatura. Tradução de Ana Lúcia de Oliveira, Maria Cristina Franco Ferraz e Paulo Pinheiro. São Paulo: Ed. 34, [1995] 2005.

KERFERD, G. B. A doutrina do logos na literatura e na retórica. In: . O movimento sofista. São Paulo: Edições Loyola, [1981] 2003.

KURTZLEBEN, D. With "Fake News", Trump Moves From Alternative Facts To Alternative Language. NPR, 2017.

MARCONDES, D. "A Tradição Cética, Os Argumentos Limitativos do Conhecimento e A Questão da Linguagem”, 1997 (Conferência).

MARTINS, H. Três caminhos na filosofia da linguagem. In: MUSSALIM, F.; BENTES, A. C. (Org.). Introduçáo à linguística: fundamentos epistemológicos, volume 3. 5. ed. Sáo Paulo: Cortez, 2011.

MCINTYRE, L. Pos-truth. Cambridge (MA): The MIT Press, 2018.

NUSSBAUM, M. "Skepticism about Practical Reason in Literature and the Law”. Harvard Law Review, n. 107/3, 714-744, January 1994.

. "Sophistry about Conventions". New Literary History, Vol. 17, No. 1, Philosophy of Science and Literary Theory. Autumn, 1985, p. 129139.

PLATÃO. Diálogos de Platão: Teeteto - Crátilo. Tradução: Carlos Alberto Nunes. Vol. IX. Belém: Ed. Universidade Federal do Pará, (Amazônica), 1973.

RORTY, R. Objetivismo, relativismo e verdade. Tradução: Marco Antônio Casanova. 2a ed. Rio de Janeiro: Relume Dumará, (Escritos filosóficos; v. 1), 2002.

SEXTUS EMPIRICUS. Contre les professeurs. Introduction, glossaire et index par Pierre Pellegrin, traduction par Catherine Dalimier, Daniel Delattre, Joëlle Delattre et Brigitte Pérez, sous la direction de Pierre Pellegrin. Paris : Le Seuil, 2002.

Esquisses pyrrhoniennes. Introduction, traduction et commentaires par Pierre Pellegrin. Paris: Le Seuil, 1997. 
STONE, M. "Wittgenstein on deconstruction" In: The new Wittgenstein. CRARY, A.; READ, R. (Eds.) London: Routledge, 2000.

TAYLOR, T. J. Mutual misunderstanding: skepticism and the theorizing of language and interpretation. Duham and London: Duke University Press, 1992.

TESICH, S. A Government os Lies. The Nation, p. 12-14, 1992.

WOLFF, F. Conversa informal, 2008. 